УАK 342.55

ББК 67.400 .7

DOI 10.22394/1682-2358-2019-6-27-35

V.V. Kbramushin, postgraduate student of the Constitutional Law Department, Saratov State Academy of Law

\section{COMMUNICATIVE FUNCTION \\ OF REPRESENTATIVE \\ DEMOCRACY \\ INSTITUTIONS \\ IN THE RUSSIAN FEDERATION}

Communicative function of representative democracy institutions in the Russian Federation is considered. It is concluded that at present at the regional and municipal levels the population lacks sufficient opportunities for feedback from deputies of representative authorities, which requires improvement of the institution of elected officials recall.

Key words and word-combinations: communication, representative democracy, representative authorities, recall of deputies.
B.B. Храмушин, аспирант кафедрог конституиионного праља Саратовской государственной юридиеской академии (email: xvitali@mail.ru)

\section{КОММУНИКАТИВНАЯ ФУНКЦИЯ ИНСТИТУТОВ ПРЕАСТАВИТЕАЬНОЙ АЕМОКРАТИИ В РОССИЙСКОЙ ФЕАЕРАЦИИ}

\footnotetext{
Аннотация. Рассматривается коммуникационная функция институтов представительной демократии в Российской Федерации. Делается вывод, что в настоящее время на региональном и муниципальном уровнях у населения отсутствуют достаточные возможности обратной связи с депутатами представительных органов власти, что требует совершенствования института отзыва выборных должностных лиц.

Ключевые слова и словосочетания: коммуникация, представительная демократия, представительные органы власти, отзыв депутатов.
}

$\mathrm{O}$ Аной из существенных функций институтов преАставительной Аемократии явмяется коммуникативная (функция коммуникации). Следует отметить, что преАставительная Аемократия по своей природе изначамьно предназначена именно Амя коммуникации между населением определенной территории и вмастными структурами. К примеру, Аемократические выборы, используемые в процессе формирования органов преАставительной вмасти, выступают канацом коммуникации, с помощью кото- 
рого население подает сигнац, демонстрирует свое отношение к тем или иным процессам, происходящим в стране и связанной с ними деятельностью властных структур. Коммуникативную функцию выполняют и Аругие институты преАставительной демократии - политические партии, общественные палаты, выборные Аолжностные миџа, подотчетные избиратемям, и т.п.

Как известно, коммуникативная функщия означает реализаџию определенных связей в обществе [1, с. 35]. При этом ее не следует отождествлять с информационно-коммуникативной функцией, которая является более широким понятием [2, с. 9-15].

В первом десятилетии XXI в. в сощиальной философии применительно к современному обществу была сформулирована так называемая теория коммуникационного пространства [3, с. 34-48; 4, с. 13-18; 5, с. 78-83; и Ар.] . Коммуникаџионное пространство выступает особой формой бытия человека, в рамках которой осуществляются возможкности организации соџиацьных интеракций и социальных связей (отношений) посреАством естественных и Аистантных каналов коммуникации [6, с. 88]. Центральный элемент коммуникационного пространства составцяют коммуникационные каналы, подлержкивающие соџиальные отношения. Каналами называют реальную или воображаемую минию соџиальной связи (контакта), обеспечивающую Авижение сообщений от коммуникатора к реципиенту.

Институты представительной демократии, как и иные соџиальные институты, образуют указанные каналы в первую очередь между народом (избирателями) и формируемыми властными институтами. Сформированные институты представительной демократии реализуют новое направцение коммуникативной функции - создание каналов связи как межАу собой, так и межАу иными структурами (в первую очередь органами власти). В Аанных направлениях проявляется, соответственно, как вертикацьная, так и горизонтальная коммуникация.

Важнейшими направцениями реацизации коммуникативной функции институтов преАставительной демократии явцяется их участие в формировании и прекращении полномочий ( ииквидации) различных органов власти, а также иных политических структур.

Рассмотрим их более подробно.

Институты представительной демократии (как представительные органы власти, так и иные) играют существенную роль в формировании различных органов вцасти, что вполне цогично. Именно в этом проявцяется закрепленный в ст. 3 Конституции РФ принџип народовластия. ЗАесь необходимо обратить внимание на функции представительных органов власти, которые, получая властный мандат непосредственно от избирателей, транслируют их волю Аругим органам вцасти, в частности участвуя в их формировании. Поскольку в данном случае речь идет о властных структурах, то данные функции третьего уровня реализуются через определенные закрепленные законодательством полномочия. По справедиивому замечанию Б.М. Аазарева, «функции сами по себе явления, конечно, не юридические, и поэтому они не могут быть элементами компетенции. Но законодатецьство возцагает на соответствующие орга- 
ны выполнение тех или иных управленческих функций, причем в различных комбинациях и применительно к различным управляемым объектам. В результате у органа возникает право и обязанность осуществлять определенные управленческие функции в определенной сфере. Такие права и обязанности и есть один из элементов компетенџии органов управления. Всякое субъективное право или обязанность есть вид и мера соответственно юридически возможного ими юридически необходимого поведения (деятельности)» $[7$, c. $40-41]$.

При сопоставцении полномочий, связанных с участием в назначении

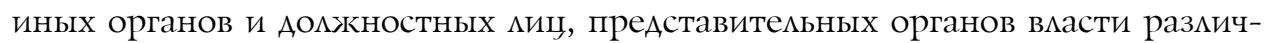
ных уровней, обращает на себя внимание следующая тенденция: чем ниже уровень власти и чем он, соответственно, ближе к населению, тем более значимы соответствующие функщии комлегиальных представительных органов. Представительный орган местного самоуправления принимает непосредственное участие и в формировании исполнительной власти, и в назначении главы муниципацьного образования. Сопоставимые функции реализуют и законодательные органы субъектов РФ, которые к тому же участвуют в формировании системы судебной власти субъекта РФ (в системе местного самоуправления муниџипальная ветвь вмасти отсутствует). Напротив, у памат Федерального Собрания РФ в этом отношении функции более ограниченны - они мишь назначают выборы Президента РФ (Совет Федерации), их участие в формировании исполнительной вмасти ограничено Аачей согласия Государственной Аумы на назначение Председателя Правительства РФ, кандидатуру которого депутаты сами предлагать неправомочны. Аругие полномочия по формированию системы исполнительной вмасти закреплены за Президентом РФ.

Соответственно, в Российской Федерации наблюдается перераспределение объема данного аспекта коммуникативной функщии органов представительной власти от комлегиальных структур к единоличной. Полномочия ПрезиАента РФ по формированию мибо участию в формировании Аругих органов власти (в особенности исполнительной) Аостаточно велики, он назначает Председателя Правительства РФ; определяет структуру федеральных органов исполнительной власти; назначает на должность заместителей Председателя Правительства РФ, федеральных министров и т.А. В Аанных случаях формально можно говорить о реацизации Президентом РФ коммуникативной функции: совершая соответствующие конституционно значимые действия, он косвенно транслирует волю избирателей, наделивших полномочиями его самого.

В то же время целесообразность сосредоточения столь значительных властных полномочий именно на федеральном уровне у одного мица видится не вполне однозначной - представительная Аемократия по своей сути в большей степени способна реализовывать свою представительскую функцию именно в комлективном воплощении. Многие ученые вполне обоснованно противопоставцяют представительные органы президенту, указывая, что историческая функция парламента заключается в ограничении абсолютистской вцасти короця ици президента [8, с. 11] и, «выступая как противовес пре- 
зидентской власти, парламентаризм предопределяет роль демократического метода» [9, с. 6-7].

Вместе с тем аналогичную тенденџию можно набцюдать и при анализе полномочий, связанных с участием институтов преАставительной демократии в прекращении полномочий (миквидации) разАичных органов власти, а также иных институтов преАставительной демократии применительно к органам преАставительной демократии.

Так, на федеральном уровне к ведению Совета Федераџии относятся:

- отрешение Президента РФ от Аолжности;

- освобождение от Аолжности Генерального прокурора РФ и заместителей Генерацьного прокурора РФ;

- освобождение от Аолжности заместителя Председателя Счетной палаты и половины состава ее аудиторов.

Государственная Аума Федерального Собрания РФ осуществляет следующие функции:

- решение вопроса о доверии Правительству РФ;

- освобожАение от должности ПреАседателя Счетной палаты и половины состава ее аудиторов;

- освобождение от Аолжности Уполномоченного по правам человека;

- выдвижение обвинения против Президента РФ Аця отрешения его от АОлжности.

Законодательные (представительные) органы субъектов РФ устанавцивают порядок отзыва высшего Аолжностного мица субъекта РФ (руководителя высшего исполнительного органа государственной вмасти субъекта РФ); освобож-

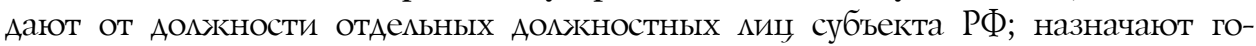
мосование по отзыву высшего должностного миџа субъекта РФ (руководителя высшего исполнительного органа государственной власти субъекта РФ); выносят решение о недоверии (Аоверии) высшему Аолжностному иицу субъекта РФ (руководителю высшего исполнительного органа государственной вцасти субъекта РФ), а также решение о недоверии (Аоверии) руководителям органов исполнительной власти субъекта РФ, в назначении которых на должность законодательный (преАставительный) орган государственной власти субъекта РФ принимац участие в соответствии с конституцией (уставом) субъекта РФ.

На этом фоне функции представительных органов муниџипальных образований, предусмотренные Федеральным законом «Об общих принџипах организации местного самоуправления в Российской Федерации», выгляАят на первый взгляд менее значимыми. Аействительно, указанный Закон прямо выделяет только одно полномочие преАставительного органа, связанное с прекращением полномочий Аругих органов вмасти - принятие решения об удалении главы муниципацьного образования в отставку. Вместе с тем уже Аанное полномочие предоставляет представительному органу значительные возможности для воздействия на иные органы власти на местном уровне. Определяется это следующими факторами:

- возможностью иниџиирования проџедуры удаления в отставку самим представительным органом (точнее, его депутатами); 
- возможностью удаления главы муниципального образования в отставку по причинам, определяемым самим представительным органом муниципального образования. Таковой является неудовлетворительная оџенка деятельности главы муниципального образования представитемьным органом муниципального образования по результатам его ежегодного отчета перед представительным органом муниципального образования, Аанная два раза подряд. Соответственно, представительному органу достаточно два раза подряд принять искцючительно субъективное решение о плохой работе главы муниципацьного образования, чтобы его отставка стала возможной;

- отсутствием необходимости получения согласия на удаление в отставку каких-либо Аругих субъектов. Правда, ч. 4 ст. 74.1 ФеАерального закона «Об общих принципах организации местного самоуправления в Российской Федерации» требует учета мнения высшего должностного миџа субъекта РФ (руководителя высшего исполнительного органа государственной власти субъекта РФ). ОАнако, как справедииво отмечает С.Е. Чаннов, в Аанном случае речь идет не о получении согласия, а мишь об учете мнения [10, с. 29], то есть, даже если указанное должностное миџо выскажет отрицательную позицию по поводу отставки, проџеАура ее вполне может быть завершена.

Аля сравнения - законодательный (представительный) орган субъекта РФ не обладает правом самостоятельно прекратить полномочия главы субъекта Федерации, а может мишь выразить ему недоверие, однако прерогатива принятия решения об отрешении от должности закрепиена за Президентом РФ. Важно также, что процедура удаления в отставку главы муниципального образования, проводимая представительным органом, явцяется не просто работающей, но и достаточно активно востребованной на практике. Так, по данным Министерства юстиџии РФ главы муниципальных образований удалялись в отставку в 2014 г. 28 раз; в 2015 - 18 раз; в 2016 - 9 раз, в 2017 - 15 раз, в 2018 - 14 раз [11].

Таким образом, можно констатировать, что представительные органы обмадают на муниципальном уровне значимым инструментом Аля вцияния на глав муниципальных образований.

При анализе вариантов взаимодействия между институтами преАставительной вмасти и иными властными структурами на разцичных уровнях их организации в целом в Российской Федерации наблюдается следующая тенАенция: чем выше уровень власти (муниципальная - региональная - федеральная), тем больше функщий по формированию и прекращению полномочий возмагается на коммегиамьные органы представительной власти. С Аругой

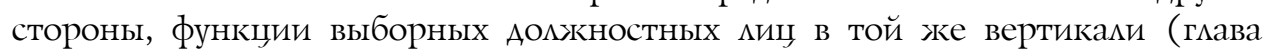
муниципального образования - глава субъекта РФ - Президент РФ), наоборот, возрастают: Президент РФ обладает несравнимо большими возможностями по воздействию на законодательную и исполнительную власть, чем главы муниципальных образований в Российской Федераџии.

С одной стороны, эта тенденция выглядит не вполне соответствующей ценностям Аемократического общества, поскольку свидетельствует о возрастании на федеральном уровне роли мичной власти при ослаблении комлегиальных на- 
чал. С Аругой, не стоит забывать, что должность Президента РФ, как уже отмечалось, относится к институтам преАставительной демократии, поскольку избирается на всенародных выборах. Аля глав муниџипальных образований такой способ замешения должности также предусмотрен действующим законодательством, однако на практике используется в отношении явного меньшинства из них. Так, по состоянию на 1 марта 2019 г. на муниципальных выборах избраны 5470 глав из 21 245, то есть 25,7\% [11]. В свою очередь, главы субъектов РФ занимают несколько промежкуточное положение - порядок наделения их полномочиями несколько раз менялся: с 1995 по 2005 г. они избирались на региональных выборах, с 2005 по 2012 г. назначались законодательными (представительными) органами субъектов РФ по представлению Президента РФ, с 2012 г. вновь избираются населением.

В силу этого полагаем, что сушествуюшая в настояшее время модель взаимодействия различных органов власти и выборных должностных Аиц с явно выраженной тенденцией к усимению комлегиальных представительных органов на муниџипальном уровне имеет право на существование, поскольку в условиях, когда указанные представительные органы часто остаются единственными, получающими мандат напрямую от населения, только они осуществляют коммуникаџионную функщию с учетом воли избирателей в отношении проводимой всеми органами и домжностными Аиџами политики. В то же время, на наш взгляА, для соблюдения баланса такая ситуаџия требует усияения контроля населения за самими представительными органами. В этом плане очевидные перспективы имеет еще один институт, представляющий собой, по мнению $\Lambda$.А. Нудненко, взаимопроникновение непосредственной и преАставительной демократии [12, с. 58-62], - отзыв избирателей. Так же как и выборы, институт отзыва выборных должностных миџ занимает промежуточное положение межАу формами прямой и преАставительной демократии, поскольку, с оАной стороны, относится к высшим формам непосредственного выражения власти народа, с Аругой - напрямую связан с функционированием представительных органов власти и выборных АОлжностных Аиц.

При этом институт отзыва избирателей по своему потенциалу явмяется, возможно, наиболее явно выраженным механизмом реализации коммуникационной функции межАу избиратемями и избираемыми ими должностными Аиџами. В отличие от выборов отзыв всегда касается конкретного Аолжностного киџа (а не группы миџ) и в рамках действующего законодательства возможен только в случае совершения данным должностным Аиџом конкретных противоправных действий. В связи с этим негативная оџенка избиратемями действий указанного Аолжностного Аица, находящая свое выражение в его отзыве (а следовательно, досрочном прекрашении полномочий), служит коммуникационным сигналом не только дмя него, но и дмя других выборных АОАжностных Аиџ, поскольку свидетельствует о вполне определенной позиџии населения по конкретным вопросам управления.

В настоящее время федеральное законодательство предусматривает отзыв депутатов и выборных должностных миџ только на муниципальном уровне. 
Такая возможность закреплена в ст. 24 и 71 Федерального закона «Об общих принципах организации местного самоуправления в Российской Федерации». В отношении регионального уровня власти действующий Федеральный закон «Об общих принщипах организаџии законодательных (представительных) и исполнительных органов государственной власти субъектов Российской Федераџии» непосредственно не регулирует Аанный вопрос, оставляя возможность сделать это субъектам РФ. ОАнако, как справеАливо отмечают специалисты, отсутствие федерального правового регулирования института отзыва депутата не способствует его широкому распространению и в региональной практике $[13$, с. 46]. В девяностые и нулевые годы законы, регламентирующие отзыв депутатов законодательных органов субъектов РФ, были приняты в целом ряде регионов, однако впоследствии большинство из них подверглось отмене. Правда, в некоторых субъектах пока еще действуют законы об отзыве глав субъектов РФ [14].

В результате, как констатирует А.Б. Сергеев, «российские граждане не имеют возможности до следующих выборов дать оџенку деятельности своих избранников в течение четырех-шести мет после их избрания, и отсутствие процедуры отзыва депутатов и всенародно избираемых должностных миц за деяния, которые не признаны судом противозаконными, дискредитирует некоторым образом и выборы: без процедуры отзыва граждане чувствуют кратковременность осушествления ими народовластия. Это всего мишь несколько минут один раз в четыре-шесть мет» [15, с. 49] .

Можно согласиться с В.А. Черепановым в том, что закрепление в Федеральном законе «Об общих принципах организации законодательных (преАставительных) и исполнительных органов государственной власти субъектов Российской Федерации» норм об отзыве региональных депутатов давно назрело [16, с. 44]. ОАнако при этом не стоит забывать и о Аругой проблеме: на муниципальном уровне, где основания и процедура отзыва предусмотрены федеральным законодательством, отзыв все равно остается неработающим институтом. Причина здесь межит в чрезмерной усложненности требований, предъявляемых к голосованию по отзыву депутата, чцена выборного органа местного самоуправления, выборного должностного миџа местного самоуправмения. В соответствии с ч. 2 ст. 24 Федерального закона «Об общих принципах организации местного самоуправления в Российской Федерации» депутат, чиен выборного органа местного самоуправления, выборное Аолжностное миџо местного самоуправления считается отозванным, если за отзыв проголосовами не менее помовины избирателей, зарегистрированных в муниципальном образовании (избирательном округе). Сложность реализации этой нормы на практике заключается в том, что законодатель в Аанном случае определил критериев отзыва проџент не от числа пришедших на голосование, а от общего количества избирателей.

МежАу тем муниципальные выборы традиционно отличаются довольно низкой по сравнению с федеральными и регионамьными выборами явкой [17] , более того, с течением времени она имеет тенденцию только к снижению $[18$, с. 14$]$. Такая индифферентность избирателей к выборам проявлялась и 
при использовании иных форм прямой демократии на местном уровне, в час-

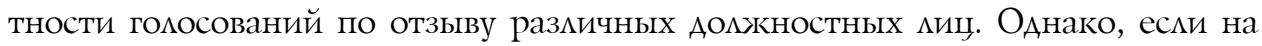
муниџипальных выборах какой-цибо минимальный порог явки избирателей отсутствует, то Аля голосования по отзыву законодатель, не устанав ивая порог явки напрямую, по сути установиц его косвенно, поскоцьку Аля того, чтобы за отзыв проголосовали не менее половины избирателей, зарегистрированных в муниџипальном образовании (избирательном округе), нужнн, чтобы, как минимум, такое же количество избирателей пришло на участки Аля голосования (в реальности, разумеется, еще больше).

Как справедииво отмечает в связи с этим П.О. Зелюков, по сути «существует правовая комиизия, когда Аля избрания депутата необходимо в несколько раз меньше голосов, чем дия его отзыва» [19]. В результате на практике даже при наличии в муниципальном образовании значительного количества избира-

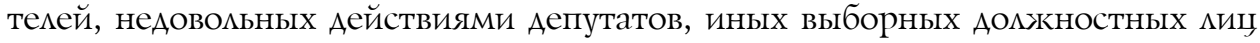
местного самоуправцения, Ааже при том, что если это неАовольство имеет поА

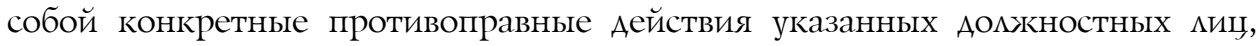
не имеют реальной возможности их отозвать [20, с. 284]. Таким образом, Аанный коммуникативный канал, призванный в Аемократических обществах играть роль обратной связи, в настоящее время в Российской ФеАерации полностью не функщионирует.

По нашему мнению, в настоящее время существует объективная необхоАимость изменения положений ФеАерального закона «Об общих принџипах организации местного самоуправления в Российской Федерации» таким образом, чтобы для принятия решения об отзыве Аепутата, выборного Аолжностного миџа местного самоуправления было достаточно простого большинства голосов избирателей, пришедших на процедуру голосования, при условии, что это число будет не меньше, чем число проголосовавших ранее за его избрание [21]. Это не только существенно повысит уровень ответственности тех же депутатов представительных органов муниципальных образований, но и поставит сами представительные органы, которые, как было отмечено, обладают значительными полномочиями по воздействию на Аругие органы и Аолжностных $и$ местного самоуправления, под серьезный и оперативный контроль со стороны избирателей.

Необходимо внести изменения и в Федеральный закон «Об общих принципах организации законодательных (представительных) и исполнительных органов государственной вмасти субъектов Российской Федераџии», преАусмотрев в нем процедуры отзыва, аналогичные указанным.

\section{Библиографический список}

1. Клебанов Л.Р. Памятники истории и культуры: правовой статус и охрана / под ред. А.В. Наумова. 2-е изд., испр. М., 2015.

2. Кокурина О.Ю. Основные функции межотраслевого института наград государства в российском праве: ценностно-нормативный подход // Административное право и процесс. 2017. № 12.

3. Миронов В.В. Современное коммуникационное пространство как фактор трансформации культуры и философии // Вестник Московского университета. Сер. 7: Философия. 2006. № 4.

34 Bulletin of the Volga Region Institute of Administration • 2019. Vol. 19. № 6 
4. Родин А.В. Коммуникационное пространство как социальная реальность: дис. ... канд. филос. наук. Саранск, 2009.

5. Сейфуллина Г.Р. Коммуникационное пространство становления личности // Вестник Карагандинского университета. Сер.: История, философия, право. 2008. № 1 (49).

6. Тихонова С.В. Правовая политика в цифровом мире: идеи, методология, доктрина. Саратов, 2015.

7. Лазарев Б.М. Компетенция органов управления. М., 1972.

8. Заикин А.А. Представительная демократия как пространство политической борьбы // Управленческое консультирование. 2016. № 3.

9. Гончаров В.В., Поярков С.Ю. Множественность конституционного порядка // Российская юстиция. 2016. № 3.

10. Чаннов C.E. Удаление глав муниципальных образований в отставку // Практика муниципального управления. 2010. № 1 .

11. URL: https://minjust.ru/razvitie-federativnyh-otnosheniy-i-mestnogo-samoupravleniya/ doklad-o-sostoyanii-i-osnovnyh

12. Нудненко Л.А. Проблемы правового регулирования отчетов выборных представителей местного сообщества перед избирателями // Конституционное и муниципальное право. 2018. № 9.

13. Федюнин С.C. Особенности нормативно-правового регулирования конституционной ответственности депутатов законодательных (представительных) органов государственной власти субъектов РФ и высших должностных лиц субъектов РФ // Конституционное и муниципальное право. 2011. № 5.

14. О порядке осуществления гражданской инициативы в Воронежской области: Закон Воронежской области от 27 июня 2007 г. № 85-O3 (в ред. от 3 нояб. 2015 г.). URL: https://base. garant.ru/18120185/

15. Сергеев Д.Б. Выборы и отзыв депутатов и избранных должностных лиц на весах российского конституционного правосудия // Государственная власть и местное самоуправление. 2019. № 1 .

16. Черепанов B.A. К вопросу об отзыве депутата законодательного (представительного) органа государственной власти субъекта Российской Федерации // Конституционное и муниципальное право. 2013. № 5 .

17. Михалева Н.А. Парламентские и президентские выборы в России (в вопросах и ответах). 2-е изд., изм. и доп. М., 2012.

18. Шастина А.Р. Об установлении конкурсных требований к кандидатам для избрания на должность главы муниципального образования // Муниципальная служба: правовые вопросы. 2019. № 3.

19. Зелюков П.О. Процедура отзыва депутата представительного органа местного самоуправления в современном российском законодательстве: специфика Самарской области // Вестник избирательной комиссии Самарской области. URL: http://vestnik-ikso163.ru/?p=1043

20. Подсумкова А.А., Чаннов С.E. Комментарий к Федеральному закону «Об общих принципах организации местного самоуправления в Российской Федерации» (постатейный) / отв. ред. С.Е. Чаннов. 4-е изд., перераб. М., 2008.

21. По делу о проверке конституционности отдельных положений Закона Красноярского края «О порядке отзыва депутата представительного органа местного самоуправления» и Закона Корякского автономного округа «О порядке отзыва депутата представительного органа местного самоуправления, выборного должностного лица местного самоуправления в Корякском автономном округе» в связи с жалобами заявителей А.Г. Злобина и Ю.А. Хнаева: постановление Конституционного Суда РФ от 2 апр. 2002 г. № 7-П // Вестник Конституционного Суда РФ. 2002. № 3. 